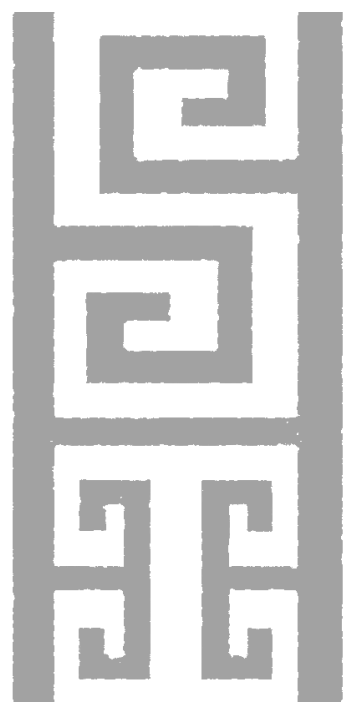

${ }^{1}$ Magíster en Ciencia Política y Administración Pública. Master of Science en Política y

Planificación Social. Director, Maestría en Política y

Planificación Social, Facultad de Ciencias Políticas y Sociales, Universidad Nacional de Cuyo. Diputado, Legislatura de la Provincia de San Juan, Argentina.

\section{Notas sobre infancia y teoría: un enfoque latinoamericano}

\author{
Notes on childhood and theory: a Latin American \\ approach
}

Bustelo Graffigna, Eduardo ${ }^{1}$

RESUMEN Este trabajo tiene como objetivo introducir y revisar algunas alternativas teóricas históricamente relevantes y plantear ciertos delineamientos que permitan desarrollar un enfoque teórico latinoamericano basado en un nuevo discurso sobre la infancia y la adolescencia. Para comenzar a elaborar un enfoque latinoamericano, entendiendo la categoría infancia como una construcción histórica y social, se parte de las aportaciones del enfoque estructural (en particular, el carácter de categoría permanente, su dimensión relacional respecto de la adultez y su dimensión histórica e intercultural) y las contribuciones de Foucault y Deleuze con el concepto de sociedad de control asociado a la categoría de dominación, muy propia del pensamiento latinoamericano. El texto corresponde a la conferencia presentada en el V Congreso Mundial por los Derechos de la Infancia y la Adolescencia realizado en San Juan, Argentina, entre el 15 y el 19 de octubre de 2012.

PALABRAS CLAVE Derechos del Niño; Adolescencia; Políticas.

ABSTRACT This work seeks to introduce and examine different historically relevant theories and propose certain frameworks that allow for the development of a Latin American theoretical approach based in a new discourse regarding childhood and adolescence. In order to undertake the creation of this Latin American approach, understanding the category of childhood as a social and historical construction, the work draws upon the contributions of structuralism (in particular, childhood as a permanent category, its relational dimension with regards to adulthood and its historical and intercultural dimension) and Foucault and Deleuze's concept of the society of control associated with the category of domination, an essential aspect of Latin American thought. The text was presented as a speech in the $\mathrm{V}$ World Congress for the Rights of Children and Adolescents held in San Juan, Argentina, from October 15-19, 2012. KEY WORDS Child Advocacy; Adolescent; Policy. 
Para el adulto, es un escándalo que el ser humano en estado de infancia sea su igual.

Françoise Dolto (1 p.13)

Desde que Ellen Key escribió El siglo de los niños (2), se ha avanzado muy lentamente en la teoría de la infancia hasta la adopción de la Convención Internacional sobre los Derechos del Niño (CIDN), que ha sido ciertamente un turning point que colocó en el centro de la escena la cuestión del sujeto y sus derechos asociados. A partir de este hecho, se ha desarrollado una larga lucha por la afirmación de los derechos de niños, niñas y adolescentes que lleva ya más de 20 años.

La afirmación de los derechos y su configuración jurídico-institucional ha significado ciertamente un avance que, como en toda lucha, registra adelantos muy significativos pero que ha tenido también un costo que podría definir como una unidimensionalidad conceptual. Por ello quiero afirmar que el derecho o las "ciencias" jurídicas han tenido una responsabilidad central en la configuración de un sujeto individual - "el" o "la" niño/a- al que se le acopla un sistema de garantías en el marco de una visión que involucraría una "protección integral". Con semejante armazón conceptual, se supone que, como resultado último, tendríamos una suerte de niño/a singularizado, blindado contra cualquier acechanza que amenace o viole sus derechos. Los saberes asociados al niño, la niña y los adolescentes son conocimientos que se apoyan principalmente en las ciencias jurídicas y, de manera subsidiaria, en la psicología y la pedagogía.

Ciertamente los saberes relacionados con la infancia son muchos, lo que configura un espacio interdisciplinario que debería incorporar muchos esfuerzos convergentes. Al derecho hay que añadir entre otras, la sociología, la filosofía, la historia, la ciencia política, la economía, la geografía, el psicoanálisis, la antropología, los saberes asociados a la educación, etc. Afirmo que hay que avanzar ahora en estos saberes y explorar otras direcciones que no necesariamente excluyen la anterior, pues la tarea del momento implica la resignificación de las luchas y la renovación de los lenguajes asociados a la infancia.

Estas notas tienen como objetivo introducir y revisar algunas alternativas teóricas históricamente relevantes y plantear algunos delineamientos que nos permitan desarrollar paso a paso un enfoque teórico latinoamericano basado en un nuevo discurso sobre la infancia y la adolescencia.

\section{SURGIMIENTO DE LA INFANCIA}

Mas allá de la discusión y debate entre el enfoque filogenético de Lloyd de Mause (3) y los planteamientos de Philippe Ariès (4) a los que considero enfoques valiosos y más que restarse se suman, creo que la cuestión -superando una historiografía de lectura "fina"- pasa por reconocer que no siempre ha habido infancia en el sentido moderno.

Haciendo un recorte y siguiendo las formulaciones de Ariès, no había infancia en la Edad Media. Las niñas eran apartadas y criadas en la vida doméstica y preparadas en su función reproductora para el matrimonio. Los niños, una vez completada sus capacidades psicomotoras, eran integrados directamente en la sociedad. No había diferencias entre niños y adultos: los niños vivían mezclados con los adultos y escogían sus propios maestros. Los niños eran considerados adultos jóvenes y, por lo tanto, la categoría infancia como instancia diferenciadora por edad no existía. La familia no tenía una función afectiva sino de conservación de los bienes y la práctica común de un oficio. Describe Ariès (4) que el afecto entre los esposos y entre los padres y los hijos no era indispensable para la existencia y el equilibrio de la familia; aunque por supuesto, si había amor y afecto, tanto mejor.

Fue recién a fines del siglo XVII que ocurrieron dos cambios fundamentales. En primer lugar en la familia, que pasó a ser un ámbito de afección entre los esposos y entre estos y sus hijos. No se trata ya de una familia constituida preferentemente en función de la propiedad y la fortuna sino en función de los hijos y de su educación. Niños y niñas salen del anonimato y se constituyen en una dimensión afectiva determinante de la familia.

En segundo lugar, la aparición de la escuela como un ámbito de encierro para disciplinar y educar a los niños. Así los niños no se mezclan más con los adultos. La escolarización marca, junto con los cambios en la familia, el 
surgimiento de la categoría infancia en el capitalismo industrial.

A partir del siglo XVIII comienza a aparecer una creciente característica endógena en la familia, que se encierra sobre ella misma en la intimidad de la vida privada diferenciándose de la sociedad. Esto va a fortalecer los procesos que buscan mayor identidad incluyendo a niños y niñas.

Ahora bien, la cuestión hoy no es tanto la identificación del origen del término sino en las distintas variedades discursivas que bajo el nombre de infancia regulan las relaciones entre adultos e infancia en la cultura.

\section{LA GRAN ASIMETRÍA}

Al realizar un análisis profundo y más allá del enfoque de derechos, estamos aún en presencia de la más formidable asimetría histórica que se resume en el Cuadro 1. Se trata de la asimetría que, en la dimensión de la cultura, expresa la relación de la infancia con la adultez predominante en la actualidad. Aquí la infancia no se refiere al niño o la niña singularizados ni a las categorías de hijo/a o alumno/a, sino al colectivo infancia que expresa el lugar que en la cultura tienen las nuevas generaciones respecto a los adultos. Esta asignación en la cultura es histórica y discursiva. La infancia es situada incuestionablemente en una relación de dependencia y subordinación.

La polaridad se complementa con una idea de linealidad que implica una transformación hacia un destino central que es el adulto. Se ponen aquí en juego las ideas de la maduración y la educación concomitante para transformarse en adulto. Hay un bildung como idea de mejoramiento y preparación personal para integrarse a través de la educación y llegar a la madurez.

En esa temporalidad hay una institucionalización de la vida en ciclos a través de secuencias claramente definidas: cuidados y estímulos en la primera infancia, escuela-educación, trabajo en la edad activa y jubilación en la vejez. Cada una de esas etapas define derechos y obligaciones y códigos culturales de pertenencia. El "yo" es una elaboración que se constituye en la subjetivación de un ser definido para el futuro: como hijo o nieto es ser como los padres o los abuelos, es decir, repetición. Surge el protoadulto: prioridad, preeminencia, superioridad adulta sobre la infancia.

Según Ravello de Castro (6), el telos de la infancia es su direccionalidad determinada para ser adulto. Ese recorrido está "normalizado" generalmente en una curva de crecimiento cuyo recorrido es universal. La socialización de la subjetividad consiste en su adaptación a un desarrollo "normalizado". Se pasa de un estado presocial a un estado social, y los desvíos son conceptualizados en términos de varianza y márgenes de error.

En este contexto, la intervención del Estado moderno se conceptualiza en términos de conseguir este tipo de sociedad racional y en equilibrio en donde se realiza el principal ajuste con la infancia a través de su condición de alumno, de su segregación por edad, y por el sometimiento a los saberes científicos a través de los cuales se "regula" la infancia.

El ser es temporal, o sea, el tiempo define el ser. Por eso, lo mejor que le puede pasar a un niño o una niña es crecer. La trayectoria del desenvolvimiento humano culmina en el adulto racional, autónomo, dueño de sí mismo. El ciclo de madurez es sinónimo de progreso lo que, a su vez, equivale a desarrollo.

Esta concepción lineal y unitaria del desarrollo humano oculta las condiciones de su producción discursiva hoy dominante y se convierte

\begin{tabular}{ll}
\hline Cuadro 1. La gran asimetría adultocéntrica. \\
\hline Adulto & Infancia \\
\hline & \\
Maduro & Inmaduro \\
Racional & Emocional (irracional) \\
Autónomo & Dependiente \\
Mayor & Menor \\
Autoridad & Obediencia \\
Competente & Incompetente \\
Completo & Incompleto \\
Público & Privado \\
Cultura & Naturaleza \\
Independiente & Dependiente \\
Trabaja & Juega \\
Actor & Objeto \\
Visible & Invisible \\
Fuerte & Vulnerable \\
Formado & Maleable \\
\end{tabular}

Fuente: Elaboración propia a partir de Alan Prout (5 p.31). 
entonces en proyecto político y cultural que frecuentemente los "científicos" vienen a legitimar.

La infancia y su asimetría colocan en el centro la cuestión de los atributos que a ella se le atribuyen y que sirven para construir los dispositivos jurídicos y culturales que la sujetan a su "pequeñez". Se trata entonces de decodificar el discurso hegemónico de la infancia y de establecer una posición crítica frontal contra las teorías que celebran la dependencia infantil. La infancia es devenir abierto, tiene una historicidad que coloca el pasado no como lo que fue sino en función de futuro como re-encantamiento del mundo.

\section{EL ENFOQUE ESTRUCTURAL}

Es fundante el análisis estructural de Jens Qvortrup (7) que propone una síntesis de nueve tesis constitutivas de la sociología de la infancia:

1) La infancia es una instancia particular y específica dentro de la estructura general de una sociedad.

2) La infancia no es una transición, una fase, un período, sino una instancia permanente.

3) La infancia es una categoría histórica e intercultural y por lo tanto es una categoría compleja.

4) Como parte integrante de una sociedad, la infancia es atravesada por la división del trabajo y las relaciones de dominación predominantes.

5) Los niños son constructores de la infancia y, por tanto, de la sociedad.

6) Las mismas relaciones macroestructurales que conforman la adultez (como por ejemplo, las relaciones económicas y las instituciones) afectan a la infancia de un modo particular.

7) Afirmar que los niños dependen de los adultos tiene como consecuencia directa su invisibilidad en los análisis históricos y sociales y su visualización como beneficiarios de un Estado "benefactor-protector".

8) La ideología "familista" (no las relaciones de parentesco) constituye un obstáculo para los intereses y el bienestar de los niños.

9) La infancia es una categoría "minorizada", achicada, "pequeñizada" y, por lo tanto, sujeta a análisis que la marginalizan o son de naturaleza paternalista. (7 p.223) (Traducción nuestra).
Como habrá de notarse, en esta formulación hay un avance notable en lo que se refiere a pensar una infancia diferenciada $y$, desde su inicio, como una categoría analítica específica e independiente en el contexto de la sociedad, con una separación a su vez muy clara de la categoría infancia de la categoría hijo, que la circunscribe solamente al ámbito privado de la familia, o de la de alumno reducida al ámbito de la escuela. La afirmación del carácter permanente de la infancia y no de su transitoriedad se transformó en una caracterización crucial y un punto de partida para pensar la infancia desde el ser y no del llegar a ser. Es el ser el que habilita definitivamente el lenguaje del sujeto y el carácter actoral de la infancia. Se inicia así una epistemología de la infancia. Niños, niñas y adolescentes son personas en estado de infancia así como los adultos son personas en estado de adultez.

Como afirma Sarmento (8), el análisis sociológico enfatiza que la categoría infancia es una construcción histórica y social y no un mero registro de la naturaleza. Se diferencia claramente por su antagonismo con la adultez, así como de otras categorías sociales como clase, género, etnia, etc., aun cuando, como se dijo, es atravesada por ellas. Este análisis se aleja epistemológicamente de las concepciones biologizantes y desarrollistas de base individualista y abstractas, como las formuladas por otras tradiciones analíticas como la psicología, particularmente la piagetiana (8). En este contexto, los niños, las niñas y los adolescentes son analizados y clasificados de acuerdo a distintos saberes pero se les niega el carácter de actores. Sin embargo, son sujetos que tienen una representación histórica específica y diferente de su localización en la cultura de los adultos. La infancia resiste la imposición de normas y valores verticalmente impuestos por el mundo de los adultos. Esta perspectiva se diferencia también de la visión sociopsicopedagógica que coloca a la infancia en el contexto de la relación social maestro-alumno, de la "formación" áulica y el ámbito pedagógico reducido a la escuela.

Lo anterior no quiere decir que la infancia sea una categoría homogénea. En realidad la infancia es una categoría homogénea respecto a la adultez que es como su exterior constitutivo. Pero es heterogénea respecto a las distintas dimensiones que la cruzan como clase social, 
etnia, género, pertenencia urbana o rural, pertenencia religiosa, lenguaje, etc.; $y$, sobre todo, a la temporalidad histórica.

\section{MÉTODOS DE INVESTIGACIÓN}

Es por ello que la infancia implica distintos modos de abordaje. Prout y James (9 p.8-9) -citados por Sarmento (8)- definen algunos puntos que consideran centrales para el desarrollo de un paradigma para la investigación de la infancia:

1) La infancia es entendida como una construcción social. Como tal, eso indica un cuadro interpretativo para la contextualización de los primeros años de la vida humana. La infancia, siendo distinta de la inmadurez biológica, no es una forma natural ni universal de los grupos humanos, mas aparece como un componente estructural y cultural específico de muchas sociedades.

2) La infancia es una variable del análisis social. Ella no puede nunca ser analizada divorciada de otras variables como la clase social, el género o la pertenencia étnica. Un análisis comparativo y multicultural revela una variedad de infancias más que un fenómeno singular y universal.

3) Las relaciones sociales establecidas por niños/as y adolescentes entre ellos y sus culturas deben ser estudiadas en sus propios términos (in their own right) independientemente de la perspectiva y de los conceptos de los adultos.

4) Niños/as y adolescentes son y deben ser vistos como actores en la construcción y determinación de sus propias vidas sociales, de las vidas de los que los rodean y de las sociedades en que viven. Niños/as y adolescentes no son sujetos pasivos de estructuras y procesos sociales.

5) Los métodos etnográficos son particularmente útiles para el estudio de la infancia. Ellos captan una voz y una participación más directa en la producción de datos sociológicos de lo que es usualmente posible a través de métodos experimentales de análisis e investigación.

6) La infancia es un fenómeno que revela agudamente la doble hermenéutica de las ciencias sociales (Giddens). Esto quiere decir que proclamar un nuevo paradigma de la sociología de la infancia es también involucrarse en el proceso de reconstrucción de la infancia en la sociedad. (Traducción del autor) (8 p.24)

La implicancia de estos seis puntos son fundamentales para entender los procesos sobre cómo investigar la infancia. Lo más significativo aquí es cómo lidiar con el adultocentrismo que impregna el método de análisis, el modo de entender y explicar el proceso de investigación, y sus conclusiones. El adultocentrismo impide el entendimiento de las circunstancias históricas, no permite el trabajo de deconstrucción del lenguaje de niños, niñas y adolescentes, no entiende la relación de poder entre adultos e infancia y no reconoce a niños y niñas como actores que tienen una vida propia intensa en la que se producen como seres sociales en interlocución con los adultos.

Martinho Ferreyra (10) ha realizado un estudio ejemplar sobre cómo descubrir a los niños y las niñas a partir de lo que ellos cuentan y de la importancia de realizar investigaciones con ellos. Afirma, acertadamente, que la infancia tiene ciudadanía epistemológica, lo que implica una sensibilidad metodológica y analítica muy particular para entender la infancia en sus propios términos, en sus códigos, en sus saberes y en sus sentimientos.

Corsaro (11) ha sido el precursor de los estudios sobre la cultura de la infancia a través de su enfoque de la "reproducción interpretativa". Este autor sostiene que los estudios interpretativos sobre la infancia están en oposición al enfoque clásico de la socialización que supone una infancia receptora y meramente pasiva. Esto quiere decir que los niños y las niñas no reproducen el orden adulto sin más, sino que lo producen en un proceso en donde reelaboran, interpretan y crean un nuevo orden de significaciones en una cultura entre pares; tienen sus propios códigos y poseen un lenguaje que desarrollan entre ellos y se apropian del lenguaje de los adultos resignificándolo en sus propios términos (a).

Lo anterior pone en cuestión la necesidad de invertir el saber adultocéntrico y sus metodologías de investigación asociadas para entender la infancia como infancia misma y desde la infancia. Las investigaciones sobre la infancia como actores sociales deben asumir la autonomía de los niños y las niñas y una simetría 
ética con los adultos. Esto implica un gran desafío en términos de una profunda reflexividad metodológica.

\section{LA SOCIEDAD DE CONTROL}

En la perspectiva de Foucault, uno podría pensar la infancia desde la violencia adulta sobre el cuerpo infantil: del "cuerpo de los suplicios, domesticado, marcado, mutilado, descompuesto, obligado, sujetado; cuerpos que son repartidos organizados, separados, reunidos" (13), en los términos de un antagonismo en donde uno se vale de la violencia y el otro la padece. La infancia es entonces una categoría relacional en la que se pone en juego el poder; relación que se devela históricamente en las prácticas (discursivas o no) y en las luchas que la atraviesan. La infancia no es un sujeto a priori o un sujeto jurídico abstracto formal sino una construcción histórica y relacional.

El pensamiento foucaultiano del sujeto no es el del sujeto instalado de una vez para siempre. O sea, un sujeto soberano al que se le atribuyen derechos. Un sujeto supuestamente autónomo, libre y singular. Por el contrario, en Foucault se trata de un sujeto atravesado de influencias sociales, políticas, culturales, históricamente determinadas. Es un sujeto producido y sujetado al orden dominador. Luego aparecen las operaciones de subjetivación que transforman los seres humanos en sujetos. En esas operaciones entra, en un primer momento, lo que Foucault Ilamaría la sociedad disciplinaria: la sociedad de los instrumentos de castigo, de la policía y de las instituciones de encierro como los asilos y las cárceles. Y también entran aquí dos pilares en la conformación de la subjetividad infantil como la familia y la escuela. La sociedad disciplinaria es la que conforma cuerpos dóciles, regularizados y clasificados y presupone un conjunto de saberes correlativos. Su método central es el panoptismo. El panóptico presupone una vigilancia central, continua, individualizada y sobre todo, tiene que hacer y mantener visible al cuerpo disciplinado $y$, al mismo tiempo, invisible y oculto al disciplinador.
Ahora bien, siguiendo a Deleuze, estamos pasando un momento transicional en donde la lógica disciplinar se somete a una lógica de control. Se conforma entonces la sociedad de control en donde la centralidad la tienen los medios de comunicación masiva. Se pasa de un biopoder centrado en el Estado para disciplinar poblaciones, a un concepto de control de públicos operado por empresas. La característica más importante es que se produce una forma de subjetivación abierta y continua en la cual lo más relevante son los flujos permanentes de informaciones, imágenes, prácticas sociales, propaganda y operaciones comunicacionales que nos mantienen bajo control. A esta forma de subjetivación Deleuze Ilama invaginación que es como el pliegue interior de la exterioridad (b). Se trata de una máquina manipuladora y controladora en funcionamiento constante cuyo rasgo central es la mercantilización de la información. Dice Deleuze:

\footnotetext{
Ahora, el instrumento de control social es el marketing, y en él se forma la raza descarada de nuestros dueños. El control se ejerce a corto plazo y mediante una rotación rápida, aunque también de forma continua e ilimitada, mientras que la disciplina tenía una larga duración, infinita y discontinua. El hombre ya no está encerrado sino endeudado. Sin duda, una constante del capitalismo sigue siendo la extrema miseria de las tres cuartas partes de la humanidad, demasiado pobres para endeudarlas, demasiado numerosas para encerrarlas: el control no tendrá que afrontar únicamente la cuestión de la difuminación de las fronteras, sino también la de los disturbios en los suburbios y guetos. (15 p.8)
}

La cuestión del público es central en el tema de la infancia ya que es allí en donde se conforma y formatea una memoria de estilos, deseos y creencias para la construcción de consumidores. Según afirma Podestá:

...si las disciplinas modulaban los cuerpos construyendo hábitos principalmente en la memoria corporal, las sociedades de control modulan cerebros y configuran hábitos principalmente en la memoria afectiva, volitiva y sensitiva. (16 p.287) 
Hemos explicado en otra publicación (17) cómo opera la máquina de control en la conformación de la subjetividad naciente de la infancia y la adolescencia. El capitalismo conoce muy bien que es allí donde puede incubar su reproducción. Aquí aparece la correlación entre formateo de la subjetividad como control y la producción de una realidad espectacularizada. Esto corresponde a la sociedad del espectáculo en términos de Guy Debord, quien en su tesis 34 afirma que "el espectáculo es el capital en un grado tal de acumulación que se ha convertido en imagen" (18 p.50). Y continúa en su tesis 42 :

\footnotetext{
El espectáculo es el momento en el cual la mercancía alcanza su ocupación total de la vida social. No es únicamente que se haga patente la relación con la mercancía, sino que ya no hay otra cosa más que esa relación: el mundo visible es su mundo. (18 p.55)
}

Central a la lógica del espectáculo es la industria del entretenimiento cuyo impacto sobre la infancia y la adolescencia ha sido ampliamente demostrado (c). La pertinencia de la perspectiva FoucaultDeleuze al análisis de la infancia no podría ser cuestionada. El paso de la disciplina al control no es lineal y hay superposiciones. Así la conformación de un cuerpo moldeable y una subjetividad controlada es central en la infancia para garantizar la trasmisión y reproducción del orden adulto que la oprime. Se están construyendo nuevas formas de subjetividad centradas en la individualidad; sujetos nómades, sin determinaciones territoriales ni políticas (20 p.182); cuerpos fragmentados y cosificados por la manipulación biotecnológica. En resumen: es la forma del nuevo estilo de la gubernamentalidad. Según Ciriza:

...el mundo capitalista [...] transforma los cuerpos en mercancía comprable y vendible en el mercado de órganos, del sexo, en el nuevo mercado de las maternidades biotecnológicas; que divide perfectamente, según clase, quienes han de disfrutar de esa maquinaria de conocimiento humano muerto que, transformado en fetiche, vuelve sobre la vida humana para dominarla. (21 p.182)

\section{LA PERSPECTIVA LATINOAMERICANA}

La visión latinoamericana es una perspectiva en formación. Dentro del pensamiento latinoamericano no existe hasta el momento una visión concreta directamente vinculada a la infancia. Pueden identificarse algunos estudios históricos a nivel nacional sobre el desarrollo de la política social, dentro de los cuales la infancia aparece identificada, pero no existe un esfuerzo teórico sistemático en términos de la infancia. Sin embargo, desde distintas ópticas han aparecido, particularmente durante la última década, estudios muy valiosos sobre problemas de niños, niñas y adolescentes desde distintas perspectivas como la filosofía, la educación, la historia, el trabajo social, la psicología social y la antropología. Existe una abundante y creciente dinámica académica (22-28). No obstante valiosos, permanece aún pendiente un esfuerzo de teorización para el desarrollo de una perspectiva de la infancia dentro de un amplio campo de visiones y diferencias.

Me propongo aquí de un manera muy provisional tender alguna líneas en gran parte ya anticipadas en El recreo de la infancia (17) (d).

Para comenzar a delinear un enfoque latinoamericano se parte de las aportaciones de enfoque estructural. En particular, el carácter de categoría permanente, su dimensión relacional respecto de la adultez y su dimensión histórica e intercultural. Aunque no uniformemente reconocido, también es importante el carácter no tan solo relacional sino antagónico de la infancia y la adultez.

También es importante e indispensable tomar en cuenta las aportaciones claves de Foucault y Deleuze. En este sentido, el concepto de sociedad de control es crucial y está muy asociado a la categoría de dominación que es muy propia del pensamiento latinoamericano. Sin embargo, lo anterior deviene de la historia. En la cuestión práctica, el orden disciplinario y de control como categorías crítico-reguladoras y superadoras del pensamiento tradicional de la socialización y desarrollo infantil es aún incipiente en Latinoamérica.

El pensamiento latinoamericano tiene desde su nacimiento un rasgo crítico muy marcante (e). Concomitantemente, es también muy 
fuerte en el pensamiento latinoamericano la categoría de dominación en el análisis de las relaciones sociales, que impregna fuertemente la categoría infancia y desde allí se desprende el rasgo emancipador. Podríamos resumir los principales rasgos del pensamiento latinoamericano del siguiente modo:

1) Una concepción de una moral emergente y la idea de dignidad humana como reguladora. La moral de la emergencia es una reconstrucción de muchas manifestaciones de diversos sectores sociales oprimidos desde la literatura popular hasta la literatura culta, y que se ha manifestado en innumerables circunstancias históricas. La moral de la emergencia surge de los que no tienen nada que perder e implica una hermenéutica crítica. La idea de dignidad humana es un a priori antropológico. El hombre/mujer no son hombre/mujer si no son dignos.

2) La humanización de las sociedades siempre surge desde abajo. Se plantea una amplia solidaridad con los oprimidos en los que se identifica una fuerte potencialidad movilizadora de cambios positivos. La humanización parte de un "nosotros" latinoamericanos lo que requiere un pensamiento con pueblo. Esta autoafirmación es la base para pensarse y ser dignos.

3) La humanización comienza con los requerimientos materiales de la dignidad humana hasta la culminación en una ciudadanía emancipada (32). Desde la necesidad se pasa a la libertad.

4) La humanización siempre es práctica, ya que se trata de generar los requisitos para una sociedad libre, igualitaria y justa. Aquí entra la práctica política. Ello implica el fortalecimiento y profundización de la democracia.

5) El pensamiento latinoamericano tiene una inspiración utópica que no es un mundo construido rígidamente sino la búsqueda de una sociedad más justa como posibilidad abierta. Se trata de la actitud utópica definida como disposición perseverante para transformar la negatividad del mundo. Esto implica la ektopia (del griego ek topos $=$ fuera de lugar, fuera del centro), lo que exige alejarse del lugar visto como espontáneamente correcto. La ektopia implica una perspectiva crítica para que la actitud utópica no descanse en una creencia definitiva. Esto se complementa con lo que Roig denomina la mirada neotópica compuesta por la comunidad de símbolos que se anudan en la conciencia colectiva orientándolas hacia la consecución de relaciones sociales crecientemente más justas (33).

Ahora bien: ¿cómo se relaciona la tradición del pensamiento latinoamericano con una perspectiva específica de la infancia que implique una primera aproximación a un enfoque latinoamericano de la misma? Aquí intento presentar algunas ideas centrales para la discusión.

La infancia es un campo social e histórico. Por campo entendemos el espacio de luchas sociales y discursivas para regular la reproducción o recomposición del statu quo. Histórico quiere decir que hay una temporalidad en donde esas luchas se configuran o reconfiguran surgiendo así nuevas discursividades. En este contexto:

1) La infancia es una categoría antagónica con la adultez que es su exterior constitutivo. Pero la relación aldultez-infancia es una relación de dominación (f). Opera, principalmente, vía el concepto de sociedades de control. La maduración y la socialización son dispositivos conceptuales centrales que son profundamente cuestionados en este proceso.

2) La infancia es una categoría estructural y no transitoria. Pero estructural en el contexto de una relación de dominación. Perspectiva crítica hacia la clásica teoría del desarrollo infantil que concibe a la infancia con un telos definitivo que culmina en la adultez.

3) La infancia es una categoría intercultural (g) y de fuerte contenido contra el paternalismo adulto. La infancia no es principalmente una teoría protectiva pues mientras más protección hay menos autonomía y menos actoralidad (h).

4) La infancia es una autonomía (36 p.58) en el contexto de una heteronomía social planteada como proyecto y construcción política. Se trata de autonomía con partencia social y no la autonomía pensada como proyecto individual.

5) La infancia es una diacronía, es una discontinuidad con el orden del statu quo. La infancia no es una fotocopia de la generación adulta. Se trata de un proceso diacrónico y no una sincronía con el orden adulto. 
6) La infancia es una categoría emancipatoria y como tal implica una teoría del cambio social. El devenir de la infancia, en tanto que transporta lo nuevo, coincide con la construcción de una sociedad justa. Y aquí se junta con la actitud utópica como principio crítico-regulativo de la práctica política.

Deseo referirme ahora al punto de la utopía, cuestión compleja a la que no puedo tocar tanto desde su aspecto general como a la abundante bibliografía sobre América Latina (i). Aquí solo quiero enfatizar que la coincidencia de utopía con infancia se da, en primer lugar, a través del concepto de incompletud. En efecto, la utopía tiene que ver con el not yet de Ernst Bloch (40), como aquello que aún no ha Ilegado pero está pronto por llegar. Es lo que no es todavía pero que se encuentra encarnado en la realidad desde donde se desprende. El futuro es entonces algo esperado, pero no como un saber teleológico preorientado sino como anticipación, cuyos principios constructivos pueden ser encontrados en el presente.

Ahora bien, parecería que mis reflexiones sobre la incompletud estarían en concordancia con el concepto de infancia como algo que no es pero que va a llegar a ser. No es así. Es preciso entonces aclarar que cuando hablo de utopía no postulo un orden acabado sino abierto pues si no la utopía sería un orden históricamente predeterminado. En este sentido, la infancia tampoco aparece predeterminada a concluir en la adultez como la forma más desarrollada del ser, ni la adultez es un estado definitivo. Igualmente, la utopía implica una propensión, una actitud que desde un por-venir interpela lo real como forma crítico-constructiva: es una interrogación abierta hacia delante como una anticipación que está enmarcada en la rebelión de una subjetividad que emerge.

Es así que nace la actitud utópica: una dimensión humana radicalmente puesta en contradicción con la negatividad del mundo presente y que busca su transformación. Allí se identifica con la infancia cuya dimensión es la creación y la renovación del presente de un mundo incompleto. Si utopía es el no lugar, la infancia es también el no lugar en el mundo adulto. Desde ese no lugar, la infancia encarna el saber rebelde contra el orden constituido enmarcado en la adultez. Así planteado, la infancia transporta las fuerzas que transforman el statu quo; ella transporta lo nuevo, la creación y por lo tanto comporta un actor sustantivo del cambio social. Desde este punto de vista, en la dualidad infancia-adulto está comprendida una teoría de cambio social. La infancia no es pensada ya como en la visión de la socialización, como algo que hay que adaptar y moldear al orden adulto, sino que representa la posibilidad de su superación.

En segundo lugar, la infancia implica una teoría de expansión de lo humano que no termina en el orden adulto opresor. Ella es una progresividad que busca lo nuevo y que interpreta, como dijimos, en sus propios términos. Pese a que hay antagonismo con el orden adulto, la infancia es una relación de tensión y dialogal. Por eso hablamos de autonomía y no de independencia. También la infancia es autonomía con pertenencia social: no se trata de la infancia contra la sociedad. Por eso la infancia deber ser entendida como una categoría histórica y estructural.

En tercer lugar, hay una categoría de tiempo en la que la infancia representa el comienzo, pero otro comienzo: un comienzo contra el statu quo adulto. Hay hoy una temporalidad que en la cultura se presenta lineal y siempre con un sentido finalista. Todo está pensado como caminando hacia el fin. Allí espera la muerte. Por eso nos definimos como hombres y mujeres mortales. La infancia en cambio orienta la temporalidad hacia el principio, hacia la generación de la vida y su potencialidad renovadora. Allí está el comienzo, el natalicio, lo que nace, lo nuevo que busca emerger. Por eso deberíamos definirnos como hombres y mujeres natales. Volver entonces a la infancia que es un retorno al comienzo generador de la vida y su capacidad inmanente de cambiar y re-encantar el mundo. 


\section{NOTAS FINALES}

a. Algunos autores hablan del perturbador concepto "pueblo infancia" puesto que niños, niñas y adolescentes tienen relaciones propias, producen sus propias significaciones y definen espacios para el desarrollo de relaciones simétricas (12).

b. Son muy recomendables aquí, en el punto de las subjetividades adolescentes, los argumentos de Urresti (14).

c. Entre los muchos que pueden ser citados está el destacado y novedoso análisis de Joel Bakan (19).

d. Las 12 tesis planteadas en el libro me parecen válidas y pertinentes.

e. Me adscribo aquí a la idea de que el pensamiento latinoamericano tiene en Arturo Roig $(29,30)$ a uno de sus principales inspiradores. Una muy buena compilación del latinoamericanismo filosófico contemporáneo puede consultarse en el texto de Jalif de Bertranou (31). Varios autores pueden reconocerse en la evolución del pensamiento latinoamericano basado en matrices europeas con formas identitarias de reflexión autóctonas. Desde el liberalismo de Alberti; el socialismo utópico de Simón Rodriguez; el radicalismo liberal de Francisco de Bilbao; el marxismo de José Carlos Mariátegui; el antiimperialimo de José Martí y el arielismo de José Enrique Rodó. En su vertiente humanista comienza con Fray Alonso de la Veracruz, Fray Bartolomé de las Casas, Eugenio María de Hostos hasta los impulsores de la filosofía de la liberación.

\section{REFERENCIAS BIBLIOGRÁFICAS}

1. Dolto F. La causa de los niños. Buenos Aires: Paidós; 1996.

2. Key E. El siglo de los niños. Barcelona: Henrich y Cía; 1906.

3. De Mause L. Historia de la infancia. Madrid: Alianza Universidad; 1982.

4. Ariès Ph. A criança e a vida familiar no Antigo Regime. Lisboa: Relógio D’Água; 1988.

5. Prout A. The future of chidhood. London: RoutledgeFalmer; 2005.

6. Ravello de Castro L. Uma teoria da infância na contemporarneidade. En: Infância e adolescência f. La infancia no es una categoría social homogénea. Ya aclaramos que está cortada por las relaciones de clase, género, etnia y diversas situaciones espaciales y locales. Es también una categoría histórica. Pero hay dimensiones que la marcan particularmente como oprimida por el orden adulto y desde este punto de vista es homogénea.

g. Es claro que la infancia está sometida "a los vaivenes del cambio social y así cada infancia es una nueva infancia, como cada tiempo es un nuevo tiempo, y el conjunto de las estructuras que componen la categoría infancia se modifica por efecto de los cambios sociales culturales y económicos, lo que conduce también a la necesaria consideración histórica como elemento de explicación de la infancia. Pero aún hay más, las diferentes posiciones que los individuos ocupan en la sociedad producen distintas experiencias y así más que de infancia, parece pertinente para algunos hablar de 'infancias' formadas en la intersección de diversos sistemas culturales y sociales, de distintos entornos físicos, naturales o artificiales" (34 p.21).

h. Aunque no sea latinoamericano conviene tener presentes las excelentes reflexiones sobre las tesis de la visión de la infancia desde la protección hechas por David Archard (35).

i. El tema de la utopía es complejo y de una amplitud bibliográfica incomparable. A título de ejemplo puede consultarse la compilación hecha por Roland Shaer, Gregory Claeys y Lyman Tower Sargent (37). Allí recomiendo especialmente el artículo de Alain Touraine: Society as Utopia. En América Latina sugiero el clásico texto de Fernando Ainsa (38) y el de Fernández Nadal (39).

na cultura do consumo [Internet]. Rio de janeiro: NAU; 1998 [citado 12 oct 2012]. p. 16-43. Disponible en: http://www.psicologia.ufrj.br/ nipiac/images/stories/livros/infancia e adolescencia na cultura do consumo.pdf

7. Qvortrup J. Childhood as social phenomenon revisited. En: Bois-Reymond $M$, Sunker R. Childhood in Europe: Approaches, trends, findings. New York: Peter Lang; 2001. p. 215-241.

8. Sarmento MJ. Sociologia da infancia: correntes e confluencias. En: Sarmento JM, Soares de Gouvea MC, organizadores. Estudos da infancia: Educaçao e Prácticas Sociais. Petrópolis: Editora Vozes; 2008. p. 17-39.

9. Prout A, James A. A new paradigm for the sociology of chidhood? Provenance, promise and problems. En: James A, Prout A, compiladores. 
Constructing and reconstructing childhood: Comtemporany issues in the sociological study of childhood. London: The Falmer Press; 1990. p. 7-31.

10. Martinho-Ferreyra MM. "Branco Demasiado" Ou... reflexôes epistemológicas, metodológicas e éticas acerca da pesquisa com crianças. En: Sarmento JM, Soares de Gouvea MC, organizadores. Estudos da infancia: Educaçao e Prácticas Sociais. Petrópolis: Editora Vozes; 2008. p. 143161.

11. Corsaro W. The sociology of childhood. California: Pine Forge Press; 2011. p. 31-63.

12. Gallo S. Infancia e poder: Algumas interrogaçôes à escola. En: Kohan WO. Devir criança da filosofia: infância da educaçao. Belo Horizonte: Autêntica; 2010. p. 109-121.

13. Foucault M. El nacimiento de la clínica: Una arqueología de la mirada médica. Buenos Aires: Siglo XXI Editores; 2008.

14. Urresti M. Nuevos procesos culturales, subjetividades adolescentes emergentes y experiencia escolar. En: Tenti Fanfani E, compilador. Nuevos temas en la agenda educativa. Buenos Aires: Siglo XXI Editores; 2008. p. 101-124.

15. Deleuze G. Post-scriptum sobre las sociedades de control. En: Conversaciones [Internet]. Valencia: Pre-Textos; 1999 [citado 12 oct 2012]. Disponible en: http://www.oei.org.ar/edumedia/pdfs/T10 Docu1_Conversaciones_Deleuze.pdf

16. Podestá B. Derivas de la cuestión biopolítica. En: Raffin M, Podestá B, editores. Problemas y debates de la tradición y la actualidad de la filosofía política. San Juan: Facultad de Filosofía, Humanidades y Artes, Universidad Nacional de San Juan; 2012.

17. Bustelo E. El capitalismo infantil. En: El Recreo de la Infancia: Argumentos para otro comienzo. Buenos Aires: Siglo XXI Editores; 2012. p. 57-88.

18. Debord G. La sociedad del espectáculo. Valencia: Pre-Textos; 2008.

19. Bakan J. Childhood under siege: How big business targets children. New York: The Free Press; 2011.

20. Araujo C, Amadeo J. Teoría política latinoamericana. Buenos Aires: Ediciones Luxemburg; 2010.
21. Ciriza A. Cuerpo y política: sobre "ciudadanías globales" y "sujetos nómades". En: Araujo C, Amadeo J. Teoría política latinoamericana. Buenos Aires: Ediciones Luxemburg; 2010.

22. Corea C, Lewkowicz I. ¿Se acabó la infancia?: Ensayo sobre la destitución de la niñez. Buenos Aires: Lumen-Hvmanitas; 1999.

23. Kohan W. Infancia entre educación y filosofía. Buenos Aires: Laertes; 2003.

24. Carli S. Niñez, pedagogía y política. Buenos Aires: Miño y Dávila Editores; 2005.

25. Narodowski M. Infancia y poder: conformación de la pedagogía moderna. Buenos Aires: Aique; 2008.

26. Llobet V. ¿Fábricas de Niños?: Las instituciones en la era de los Derechos de la Infancia. Buenos Aires: Noveduc; 2010.

27. Vasen J. Las certezas perdidas: Padres y maestros ante los desafíos del presente. Buenos Aires: Paidós; 2008.

28. Sibila P. ¿Redes o paredes? Buenos Aires: Tinta Fresca; 2012.

29. Roig AA. Teoría y crítica del pensamiento latinoamericano. Buenos Aires: Una Ventana; 2009.

30. Roig AA. Ética del poder y moralidad de la protesta. Mendoza: EDIUNC; 2002.

31. Jalif de Bertranou CA. Semillas en el tiempo. Mendoza: EDIUNC; 2001.

32. Bustelo E. Expansión de la ciudadanía y construcción democrática. En: Bustelo ES, Minujin A, compiladores. Todos entran: Propuesta para sociedades incluyentes. Bogotá: Unicef, Editorial Santillana; 1998.

33. Mahr G. El aporte de Arturo Roig a la filosofía contemporánea. En: Roig AA. Teoría y crítica del pensamiento latinoamericano. Buenos Aires: Una Ventana; 2009. p. 337-348.

34. Gaitán L. Sociología de la infancia. Madrid: Editorial Síntesis; 2006.

35. Archard D. Liberation or Caretaking? En: Children: Rights and childhood. 2nd ed. New York: Routledge; 2004. p. 70-84.

36. Freire P. Pedagogía de la Autonomía. Buenos Aires: Siglo XXI Editores; 2002. 
37. Shaer R, Claeys G, Tower Sargent L. Utopia: The search for the ideal society in the Western world. New York: The New York Public Library; 2000.

38. Ainsa F. La reconstrucción de la utopía. Buenos Aires: Ediciones del Sol; 1999.
39. Fernández Nadal E. La utopía Mirandina. En: Revolución y utopía: Francisco Miranda y la independencia hispanoamericana. Mendoza: EDIUNC; 2001. p. 297- 332.

40. Bloch E. El principio esperanza. Madrid: Editorial Trotta; 2004.

\section{FORMA DE CITAR}

Bustelo Graffigna E. Notas sobre infancia y teoría: un enfoque latinoamericano. Salud Colectiva. 2012;8(3):287-298.

Recibido el 21 de octubre de 2012

Aprobado el 16 de noviembre de 2012 